
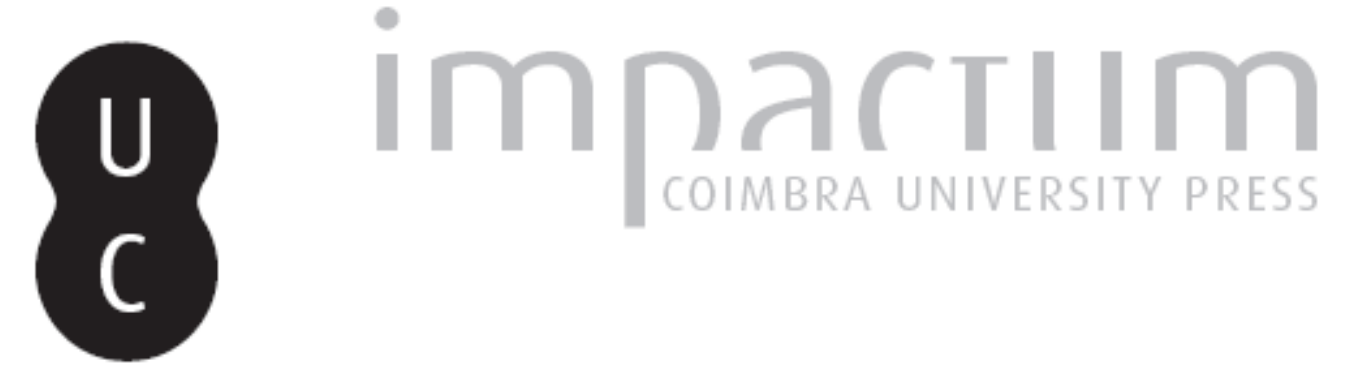
Os comités locais de gestão do risco de calamidades e a educação sobre inundações
no Baixo Limpopo, Moçambique
Autor(es):
Dgedge, Gustavo; Chemana, Célia

Publicado por: Imprensa da Universidade de Coimbra

URL persistente:

URI:http://hdl.handle.net/10316.2/44198

DOI:

DOI:https://doi.org/10.14195/1647-7723_25-2_10

Accessed : $\quad$ 26-Apr-2023 14:48:10

A navegação consulta e descarregamento dos títulos inseridos nas Bibliotecas Digitais UC Digitalis, UC Pombalina e UC Impactum, pressupõem a aceitação plena e sem reservas dos Termos e Condições de Uso destas Bibliotecas Digitais, disponíveis em https://digitalis.uc.pt/pt-pt/termos.

Conforme exposto nos referidos Termos e Condições de Uso, o descarregamento de títulos de acesso restrito requer uma licença válida de autorização devendo o utilizador aceder ao(s) documento(s) a partir de um endereço de IP da instituição detentora da supramencionada licença.

Ao utilizador é apenas permitido o descarregamento para uso pessoal, pelo que o emprego do(s) título(s) descarregado(s) para outro fim, designadamente comercial, carece de autorização do respetivo autor ou editor da obra.

Na medida em que todas as obras da UC Digitalis se encontram protegidas pelo Código do Direito de Autor e Direitos Conexos e demais legislação aplicável, toda a cópia, parcial ou total, deste documento, nos casos em que é legalmente admitida, deverá conter ou fazer-se acompanhar por este aviso.

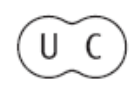




\title{
OS COMITÉS LOCAIS DE GESTÃO DO RISCO DE CALAMIDADES E A EDUCAÇÃO SOBRE INUNDAÇÕES NO BAIXO LIMPOPO, MOÇAMBIQUE*
}

\author{
THE LOCAL DISASTER RISK MANAGEMENT AND FLOOD EDUCATION COMMITTEES IN THE \\ LOWER LIMPOPO, MOZAMBIQUE
}

Gustavo Dgedge

Departamento de Geografia, Faculdade de Ciências da Terra e Ambiente Universidade de Pedagógica (Moçambique) ORCID 0000-0002-5054-8440 gudgedge@gmail.com

Célia Chemana

Departamento de Geografia, Faculdade de Ciências da Terra e Ambiente Universidade de Pedagógica (Moçambique) ORCID 0000-0001-7821-2669 celiachemana@gmail.com

\section{RESUMO}

Na gestão de riscos naturais, a educação para a redução da vulnerabilidade parte do conhecimento da realidade do local. No Baixo Limpopo foram formados Comités Locais de Gestão de Riscos de Calamidades, compostos por 18 pessoas voluntárias da Comunidade que fazem a gestão, para reduzirem a vulnerabilidade onde habitam. Estes participam nas simulações e campanhas levadas a cabo antes, durante e depois dos fenómenos calamitosos. 0 objectivo desta pesquisa foi compreender a contribuição destes Comités na educação sobre o risco de inundação no Baixo Limpopo, em Moçambique. A metodologia baseou-se na entrevista, observação directa e na consulta documental. Foram entrevistados membros dos Comités Locais de Gestão de Riscos, população e técnicos do Instituto Nacional de Gestão de Calamidades. Realizaram-se visitas de campo para identificar os locais e testemunhar as actividades de educação em matéria de gestão de riscos de inundações na comunidade. Conclui-se que os Comités promovem a educação sobre a matéria na comunidade, contribuindo na redução de vítimas mortais no Baixo Limpopo.

Palavras-chave: Comités, educação, gestão de risco, vulnerabilidade, risco.

\section{ABSTRACT}

In natural risk management, education to reduce vulnerability starts with a proper knowledge of the area. In the Lower Limpopo, Local Disaster Management Committees (CLGRCs) consist of 18 volunteers who handle the management of vulnerability reduction in their area of residence. They participate in simulations and campaigns carried out before, during and after the catastrophic phenomena. The objective of this research was to understand how these Committees contribute to flood risk education in the Lower Limpopo, Mozambique. The methodology was based on interview, direct observation and document analysis. We interviewed members of the local risk management committees, local people and technicians from the National Institute of Disaster Management. Field visits were conducted to identify sites and observe the flood risk management education activities in the community. It is concluded that the committees promote education within the community, which helps to reduce deaths in the Lower Limpopo.

Keywords: Committees, education, risk management, vulnerability, risk.

\footnotetext{
* O texto deste artigo corresponde a uma comunicação apresentada no IV Congresso Internacional de Riscos, tendo sido submetido em 15-05-2017, sujeito a revisão por pares a 22-09-2017 e aceite para publicação em 11-12-2017. Este artigo é parte integrante da Revista Territorium, $n .{ }^{\circ} 25$ (II), 2018, ${ }^{\circ}$ RIscos, ISSN: 0872-8941.
} 


\section{Introdução}

Moçambique, atravessado por rios que nascem nos países vizinhos e desaguam no seu litoral, no sudeste do continente africano, tem sido afectado por inundações de grandes dimensões que causam danos avultados nas comunidades ribeirinhas.

Nos últimos anos, com vista a reduzir a vulnerabilidade da população, foram formados Comités de Gestão de Calamidades. Estes, têm conseguido diminuir as consequências negativas das inundações a partir das acções de prevenção e de mitigação.

O presente trabalho apresenta os Comités Locais de Gestão do Risco de Calamidades e a educação sobre inundações no Baixo Limpopo, Moçambique. O mesmo foi elaborado com o objectivo de mostrar como é que os Comités contribuem para a redução dos riscos de inundação no Baixo Limpopo e apresenta o papel dos mesmos na redução da vulnerabilidade e na educação sobre as inundações.

\section{Metodologia}

A metodologia utilizada nesta pesquisa baseou-se na técnica de entrevista, a observação directa e a consulta documental. Foram entrevistados os membros dos Comités Locais de Gestão de Riscos e a população da área de estudo e técnicos do Instituto Nacional de Gestão de Calamidades, Delegação de Gaza. Realizaram-se visitas de campo para identificar os locais e testemunhar as actividades de educação em matéria de gestão de riscos de inundações na comunidade.

\section{O Baixo Limpopo}

O rio Limpopo forma-se a partir da confluência dos rios Marico e Crocodilo (que nascem a $1.500 \mathrm{~m}$ de altitude ao Oeste da Cidade de Pretoria na África do Sul) e entra em Moçambique na região de Pafúri, na província de Gaza, vindo a desaguar no Oceano Índico, em forma de estuário, perto da Cidade de Xai-Xai, em Zongoene. A pendente do curso inferior é de 0,09\% (Promexport, 1983; Pavlova, 1981).

É um rio de regime pluvial simples ou elemental do tipo pluvial tropical. A curva de caudais caracteriza-se por um só máximo e um só mínimo anual, sofrendo descenso do caudal na estação seca e aumento na estação húmida. Nos meses mais húmidos (dezembro a abril) passa na estação E-35 em Chókwè, Moçambique $91,8 \%$ do caudal anual e na estação seca (setembro a novembro) apenas 1,2\% do caudal (fig. 1).

0 rio Limpopo tem em Moçambique afluentes como o rio dos Elefantes, no qual está a Barragem de Massingir, na margem direita e o rio Changane na margem esquerda. 0 primeiro rio contribui para a inundação do Limpopo enquanto que o segundo recebe águas no período de inundação, devido a menor altitude da sua planície.

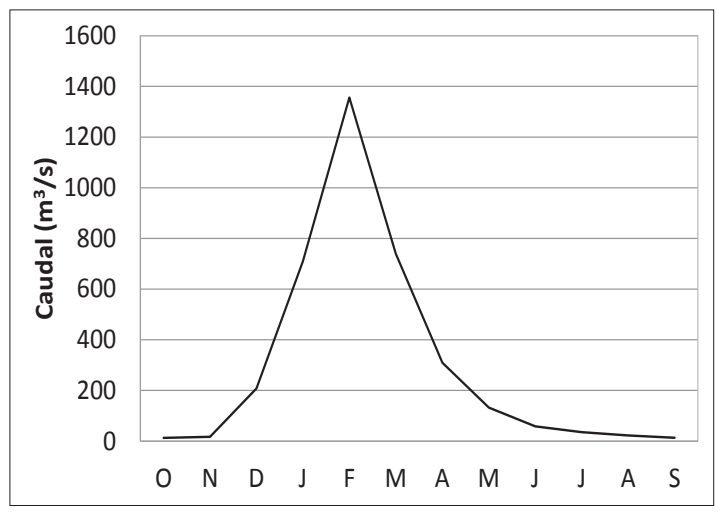

Fig. 1 - Caudal médio em $\mathrm{m}^{3} / \mathrm{s}$ na Estação E-35 de Chókwè (Fonte: Alves, 1992).

Fig. 1 - Average flow in $\mathrm{m}^{3} / \mathrm{s}$ at Chókwè Station E-35 (Source: Alves, 1992).

O Baixo Limpopo faz parte da Bacia do rio com o mesmo nome e abarca um território situado entre os paralelos $21^{\circ}$ e $25^{\circ}$ Sul e entre os meridianos $31^{\circ}$ e $35^{\circ}$ Este (fig. 2).

A área situa-se a jusante da confluência do rio Limpopo com o rio dos Elefantes, na província de Gaza, em Moçambique. A mesma é delimitada por dunas arenosas e, constitui a planície de inundação com uma pendente pequena (Savenije, 1980). Apresenta terrenos com depósitos aluviais e marinhos do quaternário superior e médio, depósitos lacustres-aluvial recentes, pantanosos e eólicos que deram origem a terraços, planícies arenosas, planícies argilo-arenoas, dunas e aluviões. Predominam sedimentos de areias finas a medias, argilomargosas e argilas,

O clima é do tipo Aw litoral junto à cidade de Xai-Xai, sendo a temperatura de media de $22,9^{\circ} \mathrm{C}$ e a pluviosidade média de $985 \mathrm{~mm}$ e, BSh no interior próximo da cidade Chókwè, onde a temperatura media é de $23,7^{\circ} \mathrm{C}$ e a pluviosidade média de $650 \mathrm{~mm}$. As chuvas caem na época quente. É uma área na qual é frequente a ocorrência de ciclones tropicais.

Habitam no Baixo Limpopo aproximadamente 250 mil pessoas nas áreas dos distritos de Chókwè, Guijá, Chibuto e Xai-Xai. As Cidade de Chókwè (205.572) e XaiXai (128.946) são as que têm mais habitantes.

A população dedica-se essencialmente a agricultura de subsistência de sequeiro, existindo em Chókwè e Xai-Xai extensas áreas de regadio onde se cultiva o arroz e hortícolas.

As vias de comunicação são na sua maioria de terra batida existindo também uma linha férrea que liga a o Porto de Maputo a República do Zimbabwe.

As casas são de construção convencional, existindo na área rural casas de construção precária (vulgo caniço - paredes de caniço e cobertura de capim ou chapa de zinco). 


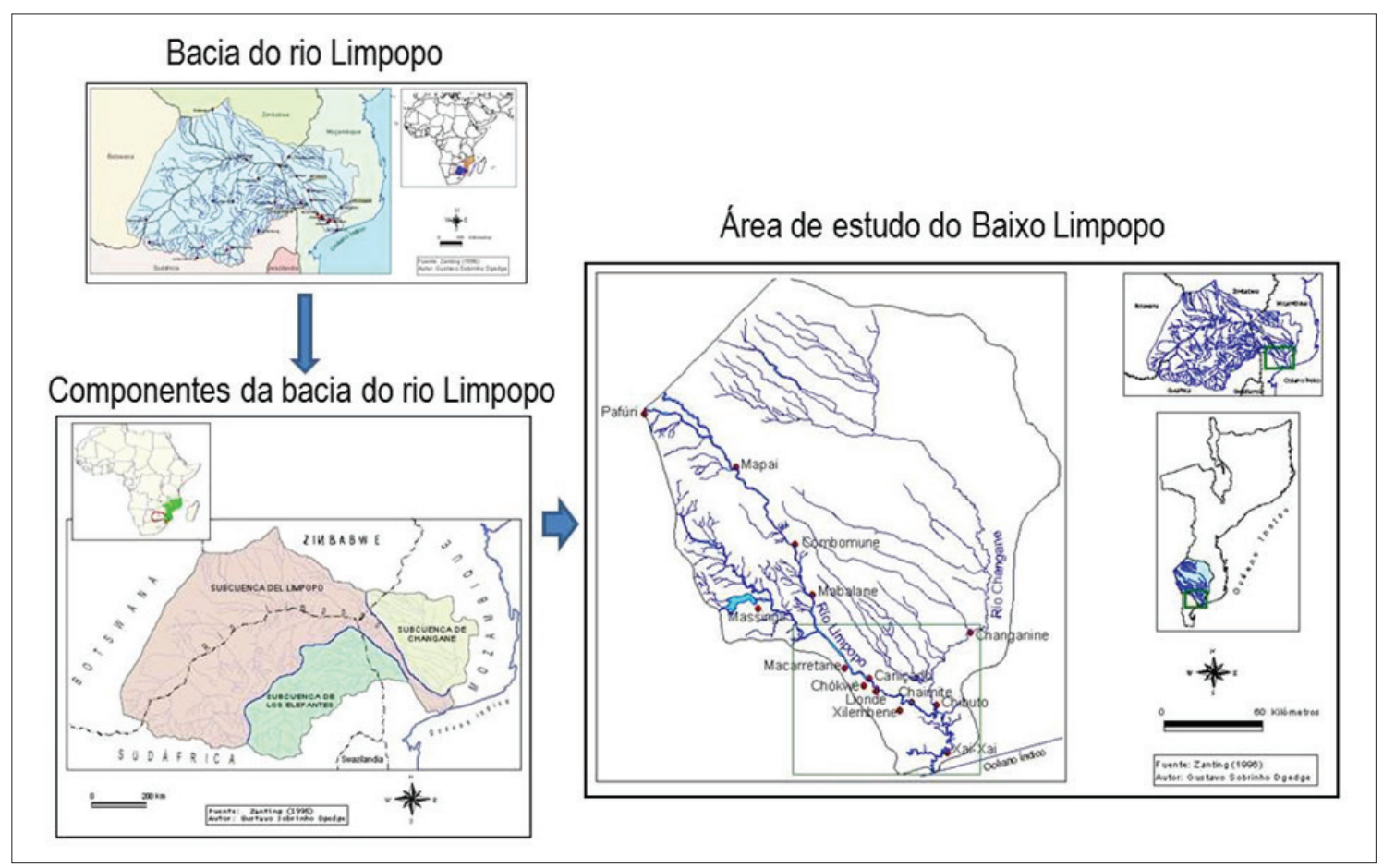

Fig. 2 - A área de estudo (Fonte: Dgedge, 2004).

Fig. 2 - The study area (Source: Dgedge, 2004).

\section{Revisão teórica}

A educação para o risco "é hoje reconhecida como uma componente da formação da criança e do jovem que importa desenvolver desde os primeiros anos de vida" (Saúde et al., 2015:5). Ela permite a adopção de comportamentos de segurança, de prevenção e gestão adequada do risco.

O risco num território resulta da ocorrência de eventos não desejados, os quais causam perdas na comunidade. Ou seja, o risco é a possibilidade de uma comunidade sofrer dano devido aos fenómenos naturais que ocorrem no território. Por isso, depende da vulnerabilidade (UNGRD, 2013). Esta última está associada a fragilidade do grupo ou comunidade na área afectada.

A maior parte dos fenómenos que em algum momento são benignos, têm culminado em "em desastres graves, ferimentos físicos, distúrbios emocionais, perda de vidas e danos materiais substanciais - ao ponto de destruir toda comunidades" (Flanagan, et al., 2011:1).

O conceito de vulnerabilidade tem, entre outras, percepções sociais, económicas e de engenharia, sendo a vulnerabilidade física um dos pré-requisitos que pode influenciar as demais vulnerabilidades, de modo que já se planejam edifícios adaptados aos riscos (Mazzorana et al., 2014; Kablan et al., 2017). Mostra-se assim que a vulnerabilidade acaba sendo determinada por vários factores combinados entre si, podendo, por isso afectar não só a própria vida, mas também os meios de subsistência. Por isso, ao incluir as características culturais, económicas existentes no território, antes, durante e depois do evento, a "noção de vulnerabilidade social em oposição a vulnerabilidade das estruturas construídas refere-se à danos potenciais para as pessoas" (Bara, 2010:4).

Considera-se, assim, que a "vulnerabilidade descreve um conjunto de condições de pessoas que derivam do histórico e prevalecente cultural, social, contextos ambientais, políticos e económicos" (Cardona e Aalst, S/A:71). Por isso, ao se analisar a vulnerabilidade devese ter em conta vários factores entre os quais a "idade ou renda, força das redes sociais e características do bairro" (Flanagan, et al., 2011:2).

Flanagan, et al. (2011) considera que ao se compreender como a população vulnerável é afectada, permite ter um conhecimento da forma como se pode alocar os recursos durante os períodos de mitigação dos desastres, desde a fase de preparação, resposta e recuperação. Mostra também que é muito importante que a comunicação do risco se faça na língua das pessoas vulneráveis para se permitir a evacuação em tempo real. Dai que seja necessário conhecer capacidade das pessoas para um perigo específico (Cardona e Aalst, S/A).

Reconhecer a vulnerabilidade como um dos elementos chaves na análise do risco, permite entender a capacidade positiva que as pessoas têm de resistir aos 
impactos dos riscos. Por isso, deve-se saber se num território existem instituições adequadas para mitigar ou responder rapidamente aos perigos que determinam a susceptibilidade ou resiliência de uma comunidade (Baas et al., 2009).

Uma das instituições que participam na gestão dos riscos são os Comités de Gestão de Riscos, os quais são recentes a nível mundial. Por exemplo, o CAPRADE (Comité Andino para a Prevenção e Atenção de Desastres) foi criado em Julho de 2002, com a participação dos países integrantes da Comunidade Andina (Bolívia, Colômbia, Equador, Peru e Venezuela), com o objectivo de contribuir para a redução do risco e do impacto dos desastres naturais e antrópicos na Sub-região Andina. O mesmo promove a difusão de políticas e actividades de previsão, mitigação, preparação, atenuação de desastres, reabilitação e reconstrução (CAPRADE, 2006).

No processo de gestão dos riscos, os Comités contribuem para o fortalecimento de capacidades no território tais como (Baas et al., 2009):

a) Incremento da capacidade e resiliência das comunidades;

b) Proteger e salvar as vidas dos cidadãos;

c) Proporcionar sistemas de aviso prévio de confiança;

d) Recuperar e reabilitar os danos.

Uma vez que as acções destinadas a reduzir a vulnerabilidade não levam o risco a um nível zero, os Comités dos Riscos visam, em geral, minimizar a magnitude de impactos de eventos extremos do risco residual (Shadeck et al., 2013). Por isso, uma vez que a Gestão de Risco de Desastres tem como objectivo a redução dos factores de risco e preparar a comunidade para uma resposta imediata quando ocorre o fenómeno (Baas et al., 2009), os Comités de Gestão de Risco tem um papel importante porque são eles que estão em contacto directo com a comunidade onde ocorrem os fenómenos danosos.

Papel dos Comités na redução da vulnerabilidade a inundações

Moçambique, sob a direcção, coordenação e supervisão do Instituto Nacional de Gestão de Calamidades (INGC, s/d), adoptou desde 2005 a Declaração de Hyogo e o Quadro de Acção 2005-2015: Construir a Resiliência das Nações e das Comunidades face aos desastres. Para tal foi colocado na agenda de governação (UNDP, 2011):

i) A redução do número de vítimas humanas e perda de propriedades;

ii) Consolidação da cultura de prevenção;

iii) A dotação no País de meios de prevenção e de mitigação, como os principais objectivos na área de gestão de desastres.
Avanços significativos foram igualmente registados no sentido de aumentar a capacidade nacional de prontidão e resposta das comunidades locais aos desastres, através do aumento desde 2007, do número e cobertura territorial dos Comités Locais de Gestão de Risco de Calamidades, atingindo em todo o território nacional, 588 comités constituídos por mais de 7200 membros, na sua maioria treinados e equipados (UNDP, 2011).

Segundo o INGC (s/d) os Comités de Gestão do Risco de Calamidades (CLGRC) são grupos formados por 15 a 18 pessoas da mesma comunidade que são criado para evitar a ocorrência de mortes de pessoas e animais e a destruição de casas, escolas, hospitais áreas de cultivo e outros bens, em caso de ocorrência de uma calamidade.

O comité do baixo Limpopo foi criado com o intuito de salvaguardar sobre eventualidades de quaisquer calamidades que poderão surgir na sua área de ação.

A área em análise é a zona baixa, propensa a cheias. Assim, o Comité não evita as cheias mas tem como missão, evitar perdas de vidas humanas e minimizar os danos nas machambas, bens materiais como utensílios domésticos, viaturas, motorizadas. "Perante a calamidade, somos nós quem chamamos a atenção. Por exemplo agora fomos anunciados que haverá uma inundação, então apenas só retiramos nossos bens da machamba e colocamos nas zonas seguras". (CP1)

Os membros devem ter o seguinte perfil:

- Pessoas capazes de trabalhar num sistema de liderança integrado;

- Pessoas voluntárias (que estejam dispostas a traba(har sem nenhuma remuneração);

- Pessoas responsáveis, com capacidade para liderar processos;

- Pessoas respeitadas na comunidade pelas autoridades comunitárias;

- Pessoas dinâmicas, criativas, motivadas, proactivas e solidarias;

- Pessoas que tenham capacidade de decisão;

- Pessoas que tenham uma visão ampla para o desenvolvimento da sua comunidade e conhecimento dos problemas da sua comunidade ou religião.

0 processo de formação pode levar em média 2 horas, num ambiente democrático, em que participa toda a comunidade, orientada por uma equipe do Instituto Nacional de Gestão de Calamidades (INGC, s/d). Os CLGRC são compostos por elementos com tarefas específicas (TABELA I).

Os Comités têm um papel muito importante na redução da vulnerabilidade na região do Baixo Limpopo porque conseguem estabelecer os mecanismos de reacção de acordo com os cenários de inundação. 
TABELA I - Tarefas dos membros dos CLGRC.

$T_{A B L E}$ I - CLGRC members' tasks.

\begin{tabular}{|c|c|c|}
\hline $\begin{array}{l}\text { Categoria de } \\
\text { Membro }\end{array}$ & Tarefas de prevenção e mitigação & Tarefas em período de emergência \\
\hline Coordenador & $\begin{array}{l}\text { Elabora, implementa e monitora o plano de acção da } \\
\text { Gestão de Risco. } \\
\text { Promove simulações locais. }\end{array}$ & $\begin{array}{l}\text { Monitora o Comité, coordena a activação e desactiva- } \\
\text { ção dos alertas locais e o apoio externo. }\end{array}$ \\
\hline $\begin{array}{l}\text { Coordenador } \\
\text { Adjunto }\end{array}$ & Mantém actualizada toda informação da comunidade. & Auxilia o coordenador no desempenho das suas tarefas \\
\hline $\begin{array}{l}\text { Responsável } \\
\text { do Kit de } \\
\text { Prontidão }\end{array}$ & $\begin{array}{l}\text { Gere os recursos locais para formar um kit e explica a } \\
\text { comunidade a utilidade do kit. }\end{array}$ & Disponibiliza o Kit para uso de acordo com as necessidades. \\
\hline $\begin{array}{l}\text { Escuta pela } \\
\text { Rádio }\end{array}$ & $\begin{array}{l}\text { Assegura o funcionamento da rádio e sensibiliza a co- } \\
\text { munidade. }\end{array}$ & $\begin{array}{l}\text { Escuta na rádio as informações sobre a evolução dos } \\
\text { fenómenos e mantem o fluxo de informação com o } \\
\text { comité e os líderes comunitários. } \\
\text { Preenche as fichas de registo de informação quando } \\
\text { ocorre um evento relevante. } \\
\text { Estabelece um mecanismo para a transmissão da } \\
\text { informação clara para todos. }\end{array}$ \\
\hline Pré-aviso & $\begin{array}{l}\text { Sensibiliza a população sobre o funcionamento do } \\
\text { Sistema de aviso e combina com a comunidade a } \\
\text { utilização de sinais tradicionais nos sistemas de } \\
\text { aviso prévio. }\end{array}$ & $\begin{array}{l}\text { Hástea as bandeiras em locais previamente identificados. } \\
\text { Manter a comunidade em constante organização para a } \\
\text { resposta a partir da divulgação dos alertas }\end{array}$ \\
\hline Evacuação & $\begin{array}{l}\text { Identifica e traça as rotas de evacuação e pontos de encontro } \\
\text { para utilização em caso de emergência, assegurando que } \\
\text { todos os membros da comunidade conheçam. } \\
\text { Elabora o plano de utilização dos recursos locais em } \\
\text { coordenação com proprietários dos meios de transporte. } \\
\text { Faz o registo da população e a actualização anual em } \\
\text { coordenação com os líderes comunitários. }\end{array}$ & $\begin{array}{l}\text { Coordena, orienta e assegura que os membros da } \\
\text { comunidade se dirijam para os locais seguros. }\end{array}$ \\
\hline $\begin{array}{l}\text { Busca e } \\
\text { Resgate }\end{array}$ & $\begin{array}{l}\text { Identifica e alista os recursos locais e a respectiva } \\
\text { localização para utilização em caso de emergência. } \\
\text { Elaborar um plano de uso dos recursos e treina a comu- } \\
\text { nidade para busca e resgate em caso de emergência. }\end{array}$ & $\begin{array}{l}\text { Executa as operações de busca e resgate em caso de } \\
\text { emergência e fornece informação sobre as pessoas } \\
\text { em perigo. }\end{array}$ \\
\hline Para Abrigo & $\begin{array}{l}\text { Identifica os locais adequados para abrigos colectivos, } \\
\text { instalação de postos de saúde e centros de distribuição } \\
\text { de alimentos. } \\
\text { Localiza fontes de água e locais para a construção } \\
\text { de latrinas. } \\
\text { Solicita capacitação na gestão dos Centros de } \\
\text { Acomodação em matérias de higiene e saneamento, } \\
\text { abastecimento, necessidades básicas, actividades } \\
\text { culturais, produtivas, recreativas, saúde mental e } \\
\text { outras condições básicas. }\end{array}$ & $\begin{array}{l}\text { Coordena o funcionamento do Centro de Acomodação, } \\
\text { apoia na distribuição de bens aos afectados e apoia os } \\
\text { Líderes Comunitários no registo das pessoas afectadas } \\
\text { nos Centros de Acomodação. }\end{array}$ \\
\hline $\begin{array}{l}\text { Gestão de } \\
\text { informação e } \\
\text { avaliação de } \\
\text { danos e } \\
\text { necessidades }\end{array}$ & $\begin{array}{l}\text { Elabora e actualiza os mapas de ameaça. } \\
\text { Faz a actualização anual da informação sobre pessoas, } \\
\text { famílias, casas, meios de transporte, serviços sociais, } \\
\text { infra-estruturas, estabelecimentos comerciais e recursos } \\
\text { naturais e ambientais existentes na comunidade. }\end{array}$ & $\begin{array}{l}\text { Faz o levantamento de dados após a ocorrência de } \\
\text { calamidades bem como das necessidades básicas e } \\
\text { solicita apoio em caso de necessidade. }\end{array}$ \\
\hline
\end{tabular}

Para a identificação dos cenários de inundação os Comités reuniram com a comunidade e auscultaram as diferentes experiências do passado e compararam as mesmas com as atuais manifestações dos fenómenos no território, produto das mudanças dos comportamentos hidrológicos do rio e das ocupações e usos do solo.

Os cenários de riscos e as acções a realizar em cada uma das situações foram construídos a partir da reconstituição das histórias e experiências dos habitantes do território em eventos passados. Foram tidos em consideração os seguintes elementos: a) 0 evoluir da dinâmica das inundações nos últimos anos tendo em conta a evolução da ocupação da planície;

b) Interesses económicos, políticos e sociais diferentes no território e as transformações realizadas no mesmo (canais de rega e drenagem, diques, estradas e pontes que alteram o processo natural da inundação);

c) Condições sociais, económicas, culturais e organizativas da comunidade e sua adaptabilidade aos novos processos de gestão de risco que envolvem 
o reassentamento (resistências a abandonar territórios ancestrais e a falta de adaptação aos novos territórios, fazendo com que se crie a inércia geográfica devido as actividades de subsistência não garantidas nos novos territórios);

d) Emergências ocorridas no passado.

Os cenários de risco permitem identificar o tipo de danos e perdas que se podem produzir. Por exemplo, é conhecido que se o alagamento for a ocorrer até determinada altura da água no solo e alagamento de certas áreas de referência como depressões, apenas serão perdidas as colheitas, não havendo necessidade de evacuar a população, mas se o leito do rio transbordar, pode haver destruição de casas e ocorrência de mortes, havendo por isso a necessidade de evacuação da população. Foram estabelecidos sinais que mostram os diferentes cenários de inundação e das acções a realizar de acordo com os mesmos, identificando as prioridades e medidas de intervenção. Por exemplo, é conhecido quando deve ser evacuado o gado, os bens materiais, as colheitas e as pessoas.

No âmbito da redução da vulnerabilidade a inundações no Baixo Limpopo, os CLGRC desenvolvem actividades antes, durante e depois dos eventos.

\section{Antes do evento}

Antes das inundações os Comités têm um papel primordial. São eles que garantem toda a acção em caso de desastre mediante acções que permitem a planificação das acções de emergência tais como:

a) Inventário das áreas perigosas de acordo com a magnitude da inundação;

b) Identificação de áreas de refúgio quando a planície se inunda;

c) Marcação de rotas de evacuação e capacitação da comunidade para a sua identificação, assim como a monitorização da sinalização criada;

d) Identificação das pessoas que necessitam de apoio em caso de inundação (anciãos, crianças, doentes e pessoas com deficiências motoras);

e) Tempos de mobilidade de acordo com a magnitude de inundação. Ou seja, os tempos de duração da evacuação no momento crítico, assim como o tipo de meio a empregar;

f) Necessidade de apoio em caso de desastre, o tempo necessário para a comunidade se recuperar e reconstruir as suas residências;

g) Prioridades de evacuação de colheitas, gado, bens, pessoas, etc.

$\mathrm{Na}$ fase de preparação para o evento, os Comités fornecem elementos muito importantes que são usados no momento do evento para respostas e recuperações pós evento. Por exemplo, colocaram marcos para sinalizar os caminhos de evacuação em caso de inundações:

"Os locais existem, locais marcados. Quando o rio encher, temos que começar a sair antes do rio chegar aqui. Então esses marcos foram colocados. Esses marcos havíamos marcados com estacas. Mas não marcamos só por marcar, informamos a população, que no local $X$, devido as características $X$, quando a água entrar devemos sair, nos que vivemos no local $X$. Sim foram mostrados os caminhos de saída. E também fomos mostrar a população. A população já sabe por onde deve sair quando estiverem inundados. Temos que evitar atravessar minambo (áreas deprimidas) porque são lugares onde a água travessa e actualmente há animais carnívoros, como por exemplo, crocodilos. Então quando alguém andar muito na água a pensar que está passar para outra margem, pode acontecer que seja atacado por esses animais.

Assim, as pessoas, desde que o Comité foi formado, já conseguem perceber, que antes da água transbordar para aqueles lugares, passamos para os lugares seguros. E Isso é que tem evitado acidentes na nossa comunidade" (CP3).

Participam na divulgação dos avisos de alerta:

“O método do comité é ficar atento. No Comité sempre que um de nós, mesmo que não seja eu o coordenador, saiba que há isto, nos avisamos. Nós já sabemos. Logo que se avisa sempre estamos a velar pelo rio, por exemplo, agora já começou entrar aquela água. Então nós fomos ver o nível das águas, portanto controlar isso" (CP2).

No grupo de trabalho, a equipe de escuta da rádio e pré-aviso responsabiliza-se por levar a informação à comunidade:

"Então ao ouvirmos transmitimos a comunidade, mesmo se as chuvas se intensificarem na comunidade ou fora do país, levamos a notícia ao Coordenador, ele ao Líder até chegar ao Posto Administrativo, que nos dias tais, haverá chuvas, essas chuvas serão grandes. Mesmo quando essa chuva se intensificar muito, se a rádio informar, informamos aos irmãos para retirarem as suas coisas das zonas baixas, nas margens, vamos sair das zonas de risco para as zonas seguras que nós conhecemos. Isso para que!? Para salvarmos as nossas vidas, as vidas dos nossos irmãos, a vida dos nossos animais que criamos que nos tem ajudado" (CP1).

Em geral, os Comités levam a cabo uma série de actividades cujo objectivo final é a prevenção e 
capacitação da população para as situações de risco, assim como também realização de atividades corretivas como limpeza de canais, criação de vias de fuga, monitorização dos processos hidrogemorfológicos, e mapeamento mental da área.

As simulações permitem evitar que a comunidade seja surpreendida por uma inundação desprovista de acções preparatórias, facto que pode levar à ocorrências de danos elevados. Por isso, exercícios simulados são periodicamente programados nessas comunidades susceptíveis, permitindo a consciencialização da mesma para os riscos a que estão expostos.

Os Comités têm trabalhado para se ter conhecimento detalhado e atualizado da dinâmica dos riscos, ao permitirem que funcione o Sistema Integrado de Informações sobre Riscos. São os Comités que dão toda a informação sobre a situação nos seus territórios ao INGC ao longo do ano, permitindo, assim, que funcione o sistema de alerta em todo o país.

\section{Durante do evento}

Durante o evento, na fase da resposta, os Comités jogam um papel importante, uma vez que uma das maiores tarefas dos Comités é proteger as pessoas e evitar a perda de vidas humanas.

Os Comités participam e auxiliam nas actividades de socorro e assistências à população afectada (apoio na logística, assistencial, cuidados de saúde, entre outros).

“Evacuação. Nós pedimos apoio as pessoas que têm viaturas aqui, pedimos apoio ao Conselho Municipal e em parceria com o INGC. Trabalhamos juntos para evacuar as pessoas para locais mais seguros" (CP5).

"Nós o Comité começamos a mobilizar, uma vez que faltando um tempo a Cruz Vermelha nos informa, o INGC também. Então convocamos a comunidade para informar que dizem que pode haver cheias, vamos nos prevenir, senão a casa pode ficar a alagar, as crianças sofrerem e os bens danificarem" (CP4).

"Convocamos toda a comunidade e explicamos que a chuva está a cair vamos nos prevenir. Usamos megafones. Quando a água já estiver a inundar, os apitos e as bandeiras. Apitamos a avisar que a água já esta se alagando, vamos nos prevenir, mesmo quando entra de noite, assim que atravessa para aqui temos comunicação com outros Comités. Questionámos, como está a água aí, também levamos bicicletas para ir verificar o que está acontecendo ao vermos que o nível da água é elevado voltamos a apitar dizendo a água está aqui vamos sair daqui. Nós esperamos o sinal. Os que tem mais riscos de serem agredidos pelas águas são os que devem sair primeiro" (CP6).

Em geral, são realizadas as seguintes actividades:

a) Protecção das vidas humanas;

b) Satisfação das necessidades básicas da população;

c) Manutenção da governabilidade do território;

d) Manter em funcionamento as diversas atividades do território;

e) Evitar maiores danos.

Os Comités permitem que em caso de inundações a população seja socorrida e atendida de forma rápida e eficiente, pois eles conhecem e fazem a monitorização da mobilidade durante o evento, tendo, por isso, conhecimento da existência de pessoas em situação de perigo.
"No caso de prontidão também eles são miniatura de unidade de protecção civil ... são os primeiros a fazerem a evacuação das famílias. Primeiro sensibilizam, as pessoas para saírem sozinhas. Eles é que mostram as rotas de evacuação, eles é que indicam para onde devem ir. Se for uma situação de haver um Centro de Acomodação, são eles também que recebem e acolhem e são eles também que ajudam para a questão da assistência, a questão do saneamento do meio, portanto, são eles que ajudam a fazer isso ai" (CP7).
"Mostramos os caminhos para chegar a escola, e depois o caminho para as casas nas zonas al- tas" (CP8).

\section{Após o evento}

A actividade dos Comités após o evento, na chamada fase de recuperação manifesta-se de varias formas, mediante a colaboração em ações tais como:

a) Indicando as prioridades de reabilitação e reconstrução;

b) Monitorizando a desobstrução de vias e limpezas de canais de drenagem;

c) Remoção e sepultamento de cadáveres humanos e de gado;

d) Descontaminação e distribuição de alimentos e meios de subsistência;

e) Monitorização da inundação para organizar o regresso dos desalojados;

f) Relocação da população nas áreas de menor risco.

Uma das tarefas do Comité depois do evento é monitorizar o processo de regresso às residências na planície que foi inundada. 


\begin{abstract}
"Nós verificamos e informamos. $E$ se eles quiserem voltar enquanto a água tiver pressão nós não deixamos. Porque há locais que quando a água ainda tiver muita corrente eu posso saltar, mas outros não. Fazemos trabalho de fiscalização" (CP 11).
\end{abstract}

Papel do Comités na educação sobre inundações no Baixo Limpopo

A gestão de riscos é da responsabilidade de todos os habitantes de um território.

Os Comités foram criados com o objectivo de permitir que a comunidade pudesse:

i. Conhecer o risco;

ii. Reduzir o risco;

iii. Conviver com o risco através das respostas em caso de emergências.

Uma das tarefas dos Comités de Gestão de Riscos é melhorar a percepção, a co-responsabilidade e a participação dos membros da Comunidade no território em risco. No Baixo Limpopo os Comités contribuem para alterar as várias percepções alimentadas pelos diferentes significados dados ao território. As crenças num regime de inundações conhecido pelos contos e histórias de seus antepassados, está a ser trocada com as novas vivências. Para tal é fundamental a existência nos Comités de indivíduos de idade avançada (acima de 60 anos) que detêm experiências e vivências de vários períodos de inundações. São estes que têm o papel de convencer aos mais novos a olhar para as novas dinâmicas dos fenómenos hidrogeomorfológicos na planície, desmistificando a não inundabilidade de algumas áreas. Para tal são apoiados pelos mais novos que acatam rapidamente os novos conhecimentos científicos e técnicos que thes são ministrados pelos diferentes organismos que actuam na planície. São criadas, assim, novas formas de ver o fenómeno de inundação e do território, antes considerado seguro, mas agora suscetível às inundações, uma vez que nos últimos anos o período de retorno passou de cinco para um ano e a magnitude dos eventos registados aumentou.

$\mathrm{Na}$ área em estudo os Comités têm um papel importante para mudar a percepção da população em relação ao risco. Uma das ações para atingir o seu objetivo é juntamente com a comunidade local identificar, a partir de eventos anteriores, as áreas que não se inundam na planície e simultaneamente, identificar os locais de maior perigo e traçam as rotas de "fuga" ou de "saída" em situação de evacuação forçada quando toda a área fica inundada.

No traçamento das rotas são utilizadas estacas para delimitar a área mais segura, sendo que no interior das mesmas é seguro e fora das mesmas é perigoso. Desde modo, torna-se possível dar diferentes significados ao território conhecido (área de cultivo, área de pasto, área de refúgio, rota de saída da área de inundação).

Os Comités de Gestão de Riscos educam a comunidade sobre a redução da vulnerabilidade na área. Para tal usam as seguintes estratégias:

a) Palestras para a população realizadas em locais de fácil acesso.

"Nos estamos a fazer a campanha para avisar mas sim nos façamos palestras ilustrativas sobre as cheias, vendavais, mais outras calamidades que podem surgir" (CP1).

Cada comunidade tem um local apropriado a que chamam de Centro. Aqui são ministrados os ensinamentos que os membros dos comités aprenderam nos cursos que frequentam ou nas trocas de experiências com outros Comités.

"Falamos sobre as cheias, amostrando aquilo que pode vir a acontecer. Chamamos atenção as pessoas para velar as suas casas, ver como estão as suas casas, e quem não tiver uma casa segura tentar se refugiar na casa do vizinho seguro. Quanto a questão de muita ventania ensinamos a saber fechar as portas e suas janelas para a casa estar consistente" (CP1).

b) Simulações realizadas com o propósito de mostrar como é que a população se deve comportar durante a ocorrência de um fenómeno real. Os membros dos comités afirmam que estes são de importância muito grande e que a comunidade utiliza os ensinamentos transmitidos.

“Aprendemos a salvar vidas humanas e o resto de coisas que pode vir a surgir perante uma calamidade. Não é só aprender por aprender só, tem suas regras para poder seguir e começar a agir se for necessário na altura exacta. A simulação ensina bem. Por exemplo, ensinamos nas simulações que nas inundações não podem andar sem um pau para lhes guiar pois há locais onde podem cair, ensinamos que devem andar de mãos dadas" (CP1).

c) Educação porta-a-porta realizada com vista a recordar a população sobre a ocorrência dos eventos perigosos. Assim, a população é capacitada para identificar as cores que indicam as diferentes magnitudes de perigo (verde, amarelo e vermelho).

Normalmente é realizada no período entre inundações, na época seca e no início da época chuvosa. Durante esta ação ensina-se a comunidade a retirar os bens antecipadamente para as áreas mais altas, assim como são relatados exemplos reais de danos ocorridos com os habitantes locais ou de outras áreas. 
No Baixo Limpopo a ameaça de inundações está no vocabulário da população. Mediante contos populares, danças, celebrações de rituais tradicionais (evocação da chamada para as chuvas, para eliminação de pragas, adorações religiosas, etc.) transmitem saberes culturais e populares sobre a gestão dos riscos. Em geral eles distinguem na língua local ndambi (inundação devido ao desbordamento do rio Limpopo) de mati ya npfula (alagamento local devido a precipitação). Temem mais o ndambi porque a água tem velocidade alta, arrasta e dificulta a saída da área alagada porque nos canais ou depressões passa a haver água a escoar com grande velocidade, havendo risco de afogamento. Contudo o mati ya npfula não thes assusta porque o alagamento é localizado e não origina escoamento de água com velocidades tal que possa arrastar pessoas, gado e bens. Neste segundo caso a duração da inundação é mais curta em relação a originada pelo desbordamento do rio. Assim também os danos porque "ela apenas molha, não mata".

A presença e actuação dos Comités na área é muito importante, uma vez que o Baixo Limpopo é uma área habitada na qual a população desenvolveu diversas formas de uso e ocupação do espaço (espiritual, habitacional, pastoril, agrícola, extrativismo). No local cada indivíduo habita o espaço de acordo com os seus interesses e necessidade, criando ali uma forma de vida. Por exemplo, vivem fazendo uma migração pendular. Durante a semana trabalham nos campos, pastam o seu gado, residindo na planície, mas aos finais de semana deslocam-se para a zona alta onde tem a segunda residência na qual estão os seus filhos em idade escolar. A planície serve como local de vida produtiva e somente saem da mesma em caso de inundação ou por necessidade de convívio familiar noutras áreas. Por isso, a população é educada para vender os excedentes agrícolas e desenvolver outras actividades de subsistências na zona alta aonde tem a segunda residência.

A acção dos Comités permite reduzir a vulnerabilidade de um território no qual os factores naturais, históricos e sociais são um grande atractivo para a população residir no mesmo.

Em geral, os Comités conseguem a participação activa e permanente de toda a população, facto que conduz à redução das pessoas expostas durante o período de inundação.

"Os comités trabalham também com os professores para difundirem a informação, nas escolas (crianças) para terem o mesmo domínio sobre a informação. Também queremos criar grupos teatrais para difundirem a informação" (CP1).

$\mathrm{Na}$ área de educação, nos últimos anos os comités treinam a população na construção de casas que resistem aos desastres, uma vez que as casas eram construídas com material precário.

\section{Conclusão}

Uma gestão adequada do risco de inundação inicia pelo conhecimento profundo do território, sua história, sua população, suas actividades, seus hábitos e comportamentos, assim como sua reacção nos casos de emergência nos diferentes cenários de risco.

Para tal, nada melhor do que criar uma organização com membros locais que vivem na comunidade, que conhecem as vulnerabilidades e podem fornecer informações fidedignas importantes para dar respostas em caso de desastre. Essa organização é o Comité de Gestão de Riscos de Desastres.

Os Comités contribuem para a redução da vulnerabilidade:

a. Física melhorando as técnicas de construção das residências.

b. Educativa - os Comités proporcionam à comunidade conhecimentos sobre o território, sobre as dinâmicas hidrogeomorfológicas, sobre o processo de inundações, sobre as acções a realizar em caso de ocorrência das mesmas. Em grande parte, são um vector da educação informal sobre o risco de inundação, sendo, por isso, responsáveis pela redução da perda de vítimas humanas.

c. Cultural - a memória coletiva é um fator importante na gestão de riscos. A história da comunidade, a sua evolução, os seus hábitos culturais e a sua forma de estar social contribuem para a mudança da percepção. Isto faz com que os mais novos possam facilmente acatar as recomendações dadas pelos anciãos e membros dos Comités, porque eles passam a ser ouvidos por terem vivenciado eventos passados. Os Comités permitem manter a memória de quem chegou primeiro ao território. Ao mesmo tempo divulgam as práticas que foram utilizadas no passado para superar ou neutralizar as situações de risco;

d. Política - a participação comunitária nos actos ou eventos organizados pelos Comités como palestras, acções de capacitação, campanhas de educação porta-a-porta, distribuição de víveres, depende muito da capacidade de gestão dos Líderes Políticos Locais. Existe uma boa relação entre os Comités e a liderança política. Este facto contribui grandemente para a redução da vulnerabilidade, uma vez que a comunidade respei- 
ta e valoriza as palavras do Líder Político, principalmente quando este participa na equipe de divulgação das melhores acções levadas a cabo pelos Comités;

e. Social - o respeito que merecem provêm, em parte, do facto de serem membros dos grupos sociais com alguns poder na comunidade (membros de famílias mais antigas, pessoas com responsabilidade social, com boa reputação social, etc.). Os Comités contribuem para a redução da vulnerabilidade devido a crença que a população tem nos mesmos. Isto deriva do facto dos Comités participarem activamente na melhoria das condições sociais das camadas mais vulneráveis. Por exemplo, quando ocorre um desastre, é o Comité que organiza o processo de distribuição dos víveres, do apoio para a reconstrução das residências, do acompanhamento dos funerais das vítimas, ou seja, estão presente nos momentos mais difíceis. Eles garantem o suprimento das necessidades básicas da comunidade;

f. Económicas - os Comités contribuem para a redução das condições de pobreza no período pós-inundação, uma vez que educam a população para criar reservas de mantimentos para os períodos críticos;

g. Ambiental - os Comités contribuem para a redução da vulnerabilidade ambiental associada a inundação através de campanhas de limpeza após as inundações com vista a minimizar os surtos de epidemias de cólera. Também fazem campanhas de limpeza para desobstrução dos canais de drenagem com vista a permitir a drenagem das áreas mais baixas, com vista a eliminar os criadoiros de mosquitos, vectores da enfermidade da malária. Durante o período de inundações e após as mesmas, quando ainda não estão disponíveis as fontes naturais de água para o consumo, distribuem material para purificar a água.

\section{Bibliografia}

Baas, S., Ramasamy, S., Pryck, J., Battista, F. (2009). Análisis de Sistemas de Gestión del Riesgo de Desastres. Una Guía. http://www.fao.org/3/ai0304s.pdf. (acedido em 30/6/17).

Bara, Corinne (2010). Factsheet Social Vulnerability to Disasters. http://www.css.ethz.ch/content/ $\mathrm{dam} /$ ethz/special-interest/gess/cis/centerfor-securities-studies/pdfs/Factsheet-SocialVulnerability.pdf. (acedido em 10/12/17).

CAPRADE - COMITÉ ANDINO PARA LA PREVENCIÓN Y ATENCIÓN DE DESASTRES (2006). http://www.indeci.gob.pe/ compend_estad/2006/1_preven/1.9_com_and.pdf. (acedido em 30/6/17).

Cardona, Omar-Dario e Aalst, Maarten K. van (S/A). Determinants of Risk: Exposure and Vulnerability. https: / / www.ipcc.ch/pdf/special-reports/srex/ SREX-Chap2_FINAL.pdf. (acedido em 10/12/17).

Dgedge, G. (2004). El riesgo de inundaciones en el Bajo Limpopo (Mozambique (Tesis Doctoral). Universidade de Alcalá. Alcalá de Henares.

Flanagan, Barry E., Gregory, Edward W., Hallisey, Elaine J., Heitgerd, Janet L. and Lewis, Brian (2011). A Social Vulnerability Index for Disaster Management.https: / /svi.cdc.gov/Documents / Data/A\%20Social\%20Vulnerability\%20Index\%20for\%20 Disaster\%20Management.pdf. (acedido em 10/12/17).

INGC (s/d). Manual de Gestão de Risco de Calamidade. Moçambique.

Kablan, Malan Ketcha Armand; Dongo, Kouassi and Coulibaly, Mamadou (2017). Assessment of Social Vulnerability to Flood in Urban Côte d'Ivoire Using the MOVE Framework. http://www.mdpi.com/se arch?q=Assessment+of+Social+Vulnerability+to+ Flood+in+Urban+C\%C3\%B4te+d\%E2\%80\%99lvoire+ Using+the+MOVE+Framework\&authors=\&article _ type=research-article\&journal=water\&section=\&spe cial_issue=\&search=Search. (acedido em 10/12/17).

Mazzorana, B., Simoni, S., Scherer, C., Gems, B., Fuchs, S. and Keiler, M. (2014). A physical approach on flood risk vulnerability of buildings. https: //www. hydrolearth-syst-sci.net/18/3817/2014/hess-18-38172014.pdf. (acedido em 10/12/17).

Saúde, A., Costa, E., Fernandes, J., Esteves, M., Amaral, M., Almeida, P., André, T. (2015). Referencial de Educação para o Risco - Educação Pré-Escolar, Ensino Básico $\left(1 .^{\circ}, 2 .^{\circ}\right.$ e $3 .^{\circ}$ ciclos) e Ensino Secundário. Ministério da Educação e Ciência, Lisboa.

Shadeck, R., Santos, M., Schnorr, T., Peixoto Filho, G. (2013). A atuação da Secretaria Nacional de Defesa Civil (SEDEC) na gestão de riscos e resposta a desastres naturais. http://www.escoladegestao. pr.gov.br/arquivos/File/2013/V_CONSAD/VI_ CONSAD/072.pdf. (acedido em 30/6/17).

UNDP - UNITED NATIONS DEVELOPMENT PROGRAMME (2011). Relatório Nacional de HFA 2009-2011. https://info. undp.org/docs/pdc/Documents/MOZ/00049421_ Relatoriol\%20HFA\%20Portugues\%202011.pdf. (acedido em 30/6/17).

UNGRD - UNIDAD NACIONAL PARA LA GESTIÓN DEL RIESGO DE DESASTRES (2013). Guía comunitária para la gestión del riesgo de desastres República de Colombia. http: / /cedir.gestiondelriesgo.gov.co/archivospdf/2 guia-comunitaria-grd.pdf. (acedido em 30/6/17). 